\title{
Teoria arquivística: mito ou banalidade?
}

\section{DOCUMENTOS}

Resumo: A teoria arquivística muitas vezes é trivial, exagerada, desnecessária ou irrelevante. Embora a teoria em outras disciplinas possa produzir novos pensamentos e estimular o progresso intelectual, a teoria arquivística não pode desempenhar um papel análogo e não pode promover a profissão arquivística. Ela tende a simplificar em excesso o que é complicado e complicar além da medida o que é simples. Muitas teorias arquivísticas são relações públicas de Babbitry ${ }^{1}$ que ameaçam estratificar excessivamente a profissão.

Palavras-chave: Teoria arquivística. Prática arquivística. Arquivologia. Historiografia.

\section{Teoría archivística: ¿mito o banalidad?}

Resumen: La teoría de los archivos con demasiada frecuencia es trivial, extremada, innecesaria o irrelevante. Mientras que la teoría en otras disciplinas puede producir nuevas ideas y estimular el progreso intelectual, la teoría archivística no puede desempeñar un papel análogo y no puede avanzar en la profesión archivística. Tiende a simplificar demasiado lo que es complicado ya complicar demasiado lo que es sencillo. Gran parte de la teoría archivística son las relaciones públicas de Babbitry que amenazan con sobre estratificar excesivamente la profesión.

Palabras clave: Teoría archivística. Práctica archivística. Archivística. Historiografía.

\footnotetext{
${ }^{1}$ Notas da tradutora: Os valores, atitudes e costumes associados à classe média americana na década de 1920 podem ser resumidos na palavra Babbitry. Ele deriva do protagonista de Babbitt, um romance satírico de Sinclair Lewis publicado em 1922. George F. Babbitt resume o estilo daqueles empresários sem imaginação e que se autovalorizam, típicos das cidades e vilas. Apesar de sua evidente prosperidade e posição social, permanecem vagamente insatisfeitos com a vida, promovendo diversas tentativas de rebelião; no entanto, no final, consideram sua necessidade de aceitação social maior do que seu desejo de escapar. Disponível em https://www.merriam-webster.com/dictionary/Babbitt. Acesso em 26 jul. 2020. Tradução nossa.

Notas sobre o artigo: Artigo publicado originalmente como: ROBERTS, John. Archival theory: myth or banality? American Archivist, v. 53, p. 110-120, 1990. Disponível em: https://americanarchivist.org/doi/pdf/10.17723/aarc.53.1.a56364w710276424. Acesso em: 5 fev. 2020. Agradecemos ao autor e ao editor da revista, pela autorização da tradução e publicação na RICl. Traduzido para o português por Shirley Carvalhêdo Franco, com revisão técnica de Cynthia Roncaglio, respectivamente membro e líder do Grupo de Pesquisa Fundamentos Históricos, Epistemológicos e Teóricos da Arquivologia - GP FHETA, certificado pelo Diretório de Grupos de Pesquisa do CNPq, vinculado ao Programa de Pós-Graduação em Ciência da Informação da Universidade de Brasília.
} 


\section{Archival Theory: myth or banality?}

Abstract: Archival theory too often is trivial, overwrought, unnecessary, or irrelevant. While theory in other disciplines can produce new insights and stimulate intellectual progress, theory in archives cannot play an analogous role and cannot advance the archival profession. It tends to oversimplify that which is complicated and to overcomplicate that which is simple. Much archival theory is public relations Babbitry that threatens to over- stratify the profession.

Key words: Archival theory. Archival Practice. Archival Science. Historiography.

Há muitos anos, o repórter da $A B C$ News, Ted Koppel, palestrou para estudantes de Jornalismo na Universidade de Maryland. Ele os aconselhou a não perderem tempo estudando Jornalismo. Recomendou que estudassem Sociologia ou Ciência Política ou alguma outra área acadêmica para ampliar o entendimento deles sobre a pauta que estivessem elaborando. Os jornalistas certamente precisam entender os símbolos do editor, saber como as aliterações podem ser convertidas em manchetes e estar familiarizados com a história da sua área. Mas Koppel asseverava que a chave do sucesso no Jornalismo é o conhecimento da substância, sobre a qual o Jornalismo enquanto disciplina acadêmica não trata, restringindo-se apenas à técnica, a qual por si só não tem mérito porque Jornalismo aprende-se na prática. ${ }^{2}$

Os serviços arquivísticos se encontram basicamente na mesma situação. Arquivistas devem ser bem versados nos componentes técnicos de suas tarefas, devem apreciar a ética de sua profissão e devem saber algo sobre a história da sua área. No entanto, funções arquivísticas são processos -- nada mais. Centrar no processo de forma excessiva, como se isso tivesse um valor acadêmico ou como se fosse o elemento essencial para o sucesso dos serviços arquivísticos, banaliza a profissão e ameaça torná-la misteriosa e narcisística. Em particular, a teoria arquivística deve ser examinada como uma forma de elevar nossa compreensão sobre a criação, aquisição e manutenção dos documentos. A teoria arquivística é amplamente irrelevante para os serviços arquivísticos por promover uma estratificação indesejável dentro da profissão e por ser intelectualmente frívola.

A teoria arquivística faz duas coisas que ameaçam profundamente a clareza de pensamento: complica em demasia o que é simples e simplifica o que é complicado. Complica ao elevar ao patamar da Filosofia aqueles procedimentos facilmente dominados pelos serviços arquivísticos, decompondo-os em fragmentos e esmiuçando-os para além do seu ponto de partida. Simplifica ao reduzir um fundo, bem como as necessidades do pesquisador, a uma série

\footnotetext{
2 Koppel: Keeping Up With Changing Public Opinion, Diamondback, 9 September 1986, 1.
} 
de fórmulas e fluxogramas, e ao ditar as demandas de aprendizagem multifacetadas de um tópico, correlacionando esse conhecimento ao conhecimento de outros tópicos, aos fundos e às necessidades dos pesquisadores.

Algumas dessas teorias são absurdamente banais, uma vez que se ocupam dos mistérios dos instrumentos de pesquisa, de unidades de descrição, de propostas sistemáticas ou de procedimentos de arquivamento por números com tipo-padrão, e de problemas cotidianos, os quais poderiam ser solucionados adequadamente por arquivistas de uma forma individual e pragmática. Por outro lado, parte dessa teoria é extravagante e ilusória, uma vez que procura invocar sistemas de valores abrangentes ou grandes sínteses. Em sua proposição mítica, é apresentada como oferecendo ideias tão impressionantes e amplamente aplicáveis que influenciam dramaticamente outras disciplinas. Entretanto, a teoria arquivística praticamente não atende à maioria das questões sobre as quais os arquivistas devem se debruçar, provendo somente uma estrutura de trabalho vaga para os esforços no âmbito dos arquivos.

Em outras disciplinas, particularmente nas ciências exatas, a teoria é a fonte. A teoria dos quarks, por exemplo, revolucionou a Física, e a teoria das placas tectônicas transformou o estudo da Paleontologia e da Geologia. Tais teorias tendem a se referir a fenômenos improváveis de observação direta ou que devem ser acurados previamente, durante período extenso, antes de serem testados. Inicialmente, os quarks foram sugeridos somente por intermédio de uma fórmula matemática e, posteriormente, extrapolados dos movimentos dos elétrons, uma vez que poderiam existir apenas enquanto estivessem escondidos dentro de partículas subnucleares e nunca podendo ser isolados e "vistos". Além de serem empiricamente incognoscíveis, tais teorias têm aplicação universal dentro de uma disciplina. Se existissem quarks, a teoria pregressa sobre partículas elementares escaparia pela janela, sendo dado um valoroso passo rumo à compreensão da grande teoria de unidade. Estando os quarks por toda parte, todas as perguntas, as respostas, bem como toda a pesquisa seria alterada. ${ }^{3}$

Os serviços arquivísticos não são nada disso! E não há um papel comparável para a teoria. Há menos necessidade de conhecimento teórico, tendo em conta que, teoricamente, o essencial no trabalho arquivístico pode ser conhecido empiricamente. Os arquivos relativos a um diretor contêm informações historicamente valiosas ou não, e um arquivista pode verificar

\footnotetext{
${ }^{3}$ Riordan, Michael. The Hunting of the Quark: A True Story of Modern Physics. New York: Simon and Shuster, 1987, p.9-12.
} 
esse fator apenas observando os documentos. Além disso, teorias têm aplicação limitada ao esforço arquivístico. Os documentos referentes a um diretor podem conter informações valiosas historicamente, enquanto documentos referentes a outro diretor podem não conter. Esses exemplos arriscam parecer deliberadamente limitados, no entanto são exemplos dos únicos problemas reais que os arquivistas devem enfrentar.

Os serviços arquivísticos são intrínseca e inescapavelmente ad hoc. Não há uma imagem global nos arquivos -- apenas um somatório infinito de pequenas imagens, as quais podem ser verificadas uma de cada vez. O único segmento que as conecta é composto pelos aspectos mais rudimentares e funcionais dos serviços arquivísticos. Seria uma distorção esforçar-se para perceber conexões ou postular temas comuns que não existem.

Em razão da infinita variabilidade do assunto, é impossível existir temas gerais referentes aos arquivos. A ensaísta francesa Simone de Beauvoir descreveu os seres humanos, certa vez, como seres "cuja essência reside em não ter essência". Tal afirmação pode ser aplicada aos arquivos. Um arquivo é semelhante a um camaleão. Não tem uma essência em si mesmo, mas assume a do seu produtor: sua história, suas teorias, seu caráter. Ao dominá-los, o arquivista dominará o assunto como um todo. Ao dominar apenas o arquivo em si, o arquivista não dominou nada. A natureza dos serviços arquivísticos muda a cada trabalho. Se um arquivista conhece o produtor dos documentos, o contexto no qual foram criados e os documentos em si, então ele ou ela tem todo o conhecimento necessário para tomar decisões arquivísticas. Se um arquivista conhece a teoria arquivística, ele ou ela não seria capaz de utilizá-la antes de aprender sobre o produtor dos documentos e sobre os documentos em si; e procedendo desse modo, não haveria necessidade de tal teoria.

A assertiva mais sedutora, porém, enganosa, sobre a teoria arquivística é que esta permitiria aos seus profissionais evitar as armadilhas reais de confiar na historiografia para orientá-los na seleção de documentos para o recolhimento. Tragicamente, muitas fontes históricas foram perdidas porque arquivistas estavam cegos pelos preconceitos de seu tempo, a ponto de ignorarem que algo importante Ihes escapava. A única forma de os arquivistas começarem a transcender esses preconceitos seria tornarem-se melhores historiadores e contribuírem para o avanço do conhecimento histórico -- porque é unicamente por meio do avanço do conhecimento histórico que qualquer pessoa poderá tornar-se sensível às lacunas no documento histórico, criadas por vieses culturais, raciais, de gênero ou por outros processos de seleção. A teoria arquivística não pode oferecer atalhos para esclarecimentos históricos, 
culturais ou sociais. Políticas justificadas de avaliação e recolhimento exigem a sabedoria de um historiador experiente, não a destreza mecânica de um arquivista bem treinado. ${ }^{4}$

Em um artigo anterior, sugeri a existência de dois tipos de teoria arquivística. Uma descreve e explica os procedimentos arquivísticos: como conceber quadros de arranjo, definir séries, reconstituir a proveniência e assim por diante. Inclui-se, nessa descrição, a literatura técnica da profissão. O segundo tipo de teoria arquivística diz respeito ao conteúdo e, mais importante, ao contexto dos documentos, e não aos processos rotineiros de controle de documentos. Ao traduzir as percepções da História, Sociologia e outras áreas para uma ideologia dos arquivos, esse tipo de teoria busca fórmulas para auxiliar os arquivistas a assumirem um papel mais ativo e independente, a desenvolverem uma percepção mais apurada daquilo que deve ser documentado e a redefinirem a missão arquivística. ${ }^{5}$

Desde a publicação daquele artigo, percebi a terceira linhagem da teoria arquivística, a qual denomino de Escola Imperial. Esta Escola Imperial da Teoria Arquivística não se confunde com os escritos de Charles M. Andrews e Lawrence Henry Gipson sobre o Império Britânico do século XVIII e não se propõe a estudar o imperialismo. Ao contrário, aparentemente pretende praticá-lo, expandindo, corajosamente, as fronteiras dos serviços arquivísticos em todos os espectros, da teoria do conhecimento às relações industriais.

Até mesmo Frank Burke descreveu grande parte da teoria do "como fazer" ("how to") como não-original, "jornalística" e "mundana". ${ }^{6}$ Fora da comunidade arquivística, teria pouco interesse. Ninguém consideraria analisar os conceitos arquivísticos ou traçar seu desenvolvimento histórico como se fosse analisar e mapear o desenvolvimento da música barroca, do existencialismo ou da poesia romântica inglesa. Claro, é bem verdade que Richard Berner dedicou um livro inteiro ao assunto. ${ }^{7}$ Conquanto o livro seja útil -- embora entediante -para o trabalho de serviços arquivísticos, o paroquialismo e a esterilidade de movimentos como

\footnotetext{
${ }^{4}$ Para uma análise cuidadosa de como alguns arquivistas tentaram usar as percepções prognósticas da historiografia recente para criar políticas de aquisições mais reflexivas da realidade social, ver Lockwood, Elizabeth K. Imponderable Matters: The Influence of New Trends in History on Appraisal at the National Archives, material não publicado, National Archives Career Intern Development System, 31 May 1989 aceito para publicação em edição futura da American Archivist.

${ }^{5}$ Roberts, John W. Archival Theory: Much Ado About Shelving, American Archivist 50 (Winter 1987): p. 66-74.

${ }^{6}$ Burke, Frank G. The Future Course of Archival Theory in the United States, American Archivist 44 (Winter 1981): p. 40-42.

${ }^{7}$ Berner, Richard C. Archival Theory and Practice in the United States: A Historical Analysis (Seattle: University of Washington Press, 1983).
} 
"tradições do manuscrito" ou "tradições dos arquivos públicos" tornam improvável a sua inclusão em cursos de civilização ocidental.

Apesar do tratamento erudito de Berner sobre os conceitos arquivísticos, estes não são suficientemente válidos enquanto expressões culturais para serem estudados academicamente. Esses conceitos apenas elucidam uma ferramenta ou mecanismo de interesse restrito, de aplicação limitada e de origem insignificante. Ademais, conceitos arquivísticos existem para facilitar o estudo de outras questões e não para serem estudados em si mesmos. Arquivos atendem às necessidades de quaisquer disciplinas que exijam documentos para suas investigações e não existiriam sem aquelas disciplinas. O campo arquivístico, portanto, não tem um vigor intelectual genuinamente independente.

Do mesmo modo, estudos atuais aprofundados sobre conceitos práticos não produzem novas descobertas mas, apenas reafirmam as antigas, de forma crescente e desnecessariamente rebuscada. Embora seja útil profissionalmente enunciar os vários componentes que formam a base dos serviços arquivísticos, suas investigações acadêmicas atingem rapidamente um ponto de retorno decrescente. Mesmo com a introdução de novas tecnologias, não há nada de realmente inovador sob o sol, no sentido de como fazer teoria arquivística. No entanto, os trabalhos sobre como fazer teoria continuam a avançar, em grande parte para dividir e subdividir, afirmar e reafirmar, anexar e reanexar o mesmo território antigo.

A estratégia de documentação e a teoria de avaliação de pesos e medidas, por exemplo, não representam desvios conceituais e sim ecos amplificados. Em "O processo da estratégia de documentação: um modelo e um estudo de caso", Larry Hackman e Joan Warnow-Blewitt propõem um modelo que obrigaria os arquivistas a decidirem aquilo que é importante o suficiente para ser documentado, a determinarem a natureza de todos os documentos disponíveis, a medirem o valor de documentos para produtores e pesquisadores, a considerarem até que ponto a documentação é única, a persuadirem os produtores a melhorar suas práticas de manutenção de documentos e a divulgarem as suas aquisições. Os arquivistas, é claro, sempre tentaram realizar essas tarefas. Dessa forma, pode ser que o comentário mais explícito no artigo tenha sido aquele utilizado para descrever um princípio central do modelo: "Essa não é uma ideia inovadora e talvez seja óbvia demais para exigir discussão". Tudo o que Hackman e Warnow-Blewitt acrescentam de fato é um certo fervor religioso em relação à 
indivisibilidade dos arquivos e uma estrutura para aumentar a consulta no processo de documentação por meio do uso de comitês. ${ }^{8}$

A propósito, Hackman e Warnow-Blewitt baseiam-se em modelo desenvolvido pelo comitê ad hoc do American Institute of Physics. ${ }^{9}$ Um plano semelhante, elaborado por um grupo de trabalho do Bureau of Prisons, levou ao estabelecimento do Bureau's Office of Archives. ${ }^{10} \mathrm{O}$ fato de que um grupo de físicos, na década de 1960, e um grupo de diretores e professores de justiça criminal, na década de 1980, trabalhando independentemente uns dos outros e sem qualquer treinamento arquivístico, pudessem apresentar estratégias de análises de documentos semelhantes ao modelo de Hackman/ Warnow-Blewitt, reflete a necessidade de bolsas de estudos e formação em arquivos.

Além de compilar o óbvio, a teoria do "como fazer" coloca-a sob um microscópio eletrônico e faz a varredura de cada átomo. Em Explorando Segredos [Exploring the Black Box], Julia Marks Young e Frank Boles tentam capturar todas as complexidades do processo de avaliação. Onde Theodore Schellenberg erigiu algumas vigas, Young e Boles acrescentam paredes, torres, gárgulas e varandas, ao proporem pelo menos cinquenta e oito categorias em três módulos separados e inter-relacionados para embasar as decisões de avaliação. ${ }^{11}$

O elemento mais difícil da avaliação é decidir quais assuntos, organizações ou indivíduos exigem documentação. Essa decisão não pode ser concretizada com um processo mecânico atravancando a operação. Deve-se basear num amplo conhecimento da História, eventos atuais e até filosofias; e esse conhecimento muda e se avoluma de modo permanente, e não pode ser captado em uma simples receita. Uma vez tomada a decisão principal, as diretrizes podem estruturar a avaliação de um arquivista sobre os documentos, mas diretrizes excessivamente intrincadas não facilitam o processo ou corroboram o seu entendimento.

Num trabalho cuidadoso e louvável, Young e Boles identificaram a multiplicidade de fatores intelectuais, políticos, econômicos, técnicos, gerenciais e até emocionais, que afetam as decisões de avaliação. Embora todos esses aspectos tenham sido contemplados é questionável o valor de um único modelo que abarque todos esses fatores.

\footnotetext{
${ }^{8}$ Hackman, Larry; Warnow-Blewitt, Joan. The Documentation Strategy Process: A Model and Case Study, American Archivist 50 (Winter 1987): p. 12-47. A citação é da p.46.

9 Ibid., 17, p. 30-31.

${ }^{10}$ Fundo: BOP Archives Advisory Board, BOP Archives, Washington, DC.

${ }^{11}$ Boles, Frank; Young, Julia Marks. Exploring the Black Box: The Appraisal of University Administration Records, American Archivist 48 (Spring 1985): p.121-40.
} 
Com base no número de caixas nos fluxogramas principais, o modelo contém cinquenta e oito categorias. É provável que outras categorias poderiam ser adicionadas ao modelo. Em vez de cinquenta e oito, poderia haver cento e cinquenta e oito categorias. Ou, seguindo esse pensamento, o modelo poderia ser mais conciso. Com apenas três categorias, representando os três módulos, sem a tentativa de mencionar tudo. O problema é encontrar o equilíbrio: qual seria o nível de análise adequado? Qual nível é útil? Qual nível é excessivo? Qual nível é desnecessário?

Na verdade, muitas decisões de avaliação podem ser tomadas com base em apenas duas ou três categorias das cinquenta e oito existentes. Seria supérfluo completar todos os níveis dos três módulos. Decisões sobre algo obviamente valioso como os diários de John Quincy Adams, ou obviamente tão inúteis quanto os recibos da lavanderia Harold Stassen, poderiam ser realizadas de modo simples, com base na seção de "análise de conteúdo", no módulo "valor da informação". Não haveria necessidade de considerar as cinquenta e sete categorias restantes, somente nos casos em que houvesse documentos de valor ínfimo ou instituições com políticas de aquisição pouco esclarecedoras.

Surge, dessa forma, uma filosofia de preservação engessada em si mesma. A obsessão de compor e seguir as engenhocas de Rube Goldberg, pretendendo incorporar todas as nuanças imagináveis, leva os arquivistas ao tipo de situação que Jane Addams designou como "a armadilha da preparação". ${ }^{12}$ Hiper reestruturação, planejamento excessivo, abstração e treinamentos exagerados não compensam. Em um dado momento, torna-se inconveniente desviar a energia do trabalho real para o desenvolvimento e idolatria de construções sem essência. É possível que esse modelo venha um pouco depois das duas categorias propostas por Schellenberg e que seja muito anterior às cinquenta e oito de Boles e Young.

O problema reside na tentativa de mecanizar processos que não podem ser mecanizados e de enquadrar atividades não científicas em bases científicas. Nenhum modelo, independente de quão completo seja, teria a capacidade de medir a necessidade do pesquisador ou o valor do conteúdo, e determinar a permanência do arquivamento com a precisão que um espectrógrafo, pode medir as ondas de luz e determinar a sua composição química. O processo é cientificamente falho, levando em consideração que as informações inseridas na estrutura representam invariavelmente uma avaliação subjetiva e que o modelo pode ser difuso, invalidando a decisão. O processo de avaliação, auxiliado por algumas

\footnotetext{
${ }^{12}$ Addams, Jane. Twenty Years at Hull House (Selo clássico de reimpressão da edição de 1910), p. 63-64.
} 
sugestões sobre o que considerar, em vez de ser pressionado por ideias de teóricos sobre a verdade do arquivamento, deve ser recriado a cada nova avaliação. Distintos avaliadores, documentos, assuntos e repositórios produzirão combinações em constante mutação de fontes de informação, de processos de pensamento e de sistemas de valores. A aplicação impecável de um modelo pseudocientífico não produzirá uma boa avaliação dos documentos, assim como uma caligrafia impecável não produzirá um bom romance.

Franzir a testa sobre essas questões ilustra a falácia essencial da pesquisa em arquivo: a incompreensão daquilo que define o processo é a chave do processo. Em certo sentido, é desnecessário entender o processo, porque o processo é apenas uma questão de estilo ou técnica. Mesmo se houvesse um verdadeiro método para fazer as coisas, seria uma verdade trivial. Crie uma teoria de avaliação próxima à perfeição e essa não fará muita diferença. Aplique o modelo Young/Boles nos arquivos do Departamento de Estado, avaliados com modelos inadequados, e os diversos erros cometidos durante aquele processo não serão perceptíveis; independentemente do modelo aplicado, o arquivamento decimal central estaria a salvo, mas os comprovantes de viagem teriam sido descartados. O processo em si não é o desafio nos serviços arquivísticos, muito menos a tarefa de analisá-lo. o trabalho pensante e exigente dos arquivos é externo a eles; está enraizado na base do conhecimento de um arquivista. Se positivo, é irrelevante o estilo que cada arquivista adota.

Não somente na avaliação, como em qualquer fase dos serviços arquivísticos, os experimentos para testar os modelos teóricos devem ser realizados de forma a ceifar os excessos, uma vez que não serão descobertas leis imutáveis, como as da Física, e sim princípios vazios, como aqueles da Administração. Tais experimentos tendem a se concentrar num processo simulado, sem importância e sem resposta. A pesquisa de Richard Lytle sobre a teoria da recuperação, por exemplo, não pode ser aplicada além dos documentos sob a sua própria custódia. A adequação do método de recuperação pode, facilmente, variar de acordo com os documentos, o fundo ou os pesquisadores. Dentre dez solicitações de pesquisa irrealisticamente específicas, mesmo que a indexação de conteúdo atinja todas elas, enquanto o método de proveniência atinja apenas uma, ainda assim a proveniência terá uma validade insubstituível. Mediante a utilização de pacotes de software prontos para o uso, qualquer arquivista está habilitado a criar um plano de indexação de conteúdo e, mesmo que imperfeito, ainda compatível com a proveniência, sendo esse aspecto um ponto discutível. Toda a controvérsia, conforme exposto na obra de Richard Berner, reduz os arquivistas àquele patamar de discussões 
referentes à quantidade de informações que devem ser incluídas nos títulos das pastas, como se algum arquivista pudesse se beneficiar de deliberações teóricas sobre tal problema. ${ }^{13}$

Mesmo repleta de banalidades, e retificação não esclarecedora, a primeira escola de teoria arquivística pelo menos possui a vantagem de ter sido dedicada aos serviços arquivísticos. As outras escolas se voltam para outros fins. Embora essas escolas estejam corretas ao orientar que os arquivistas devem confiar em outras disciplinas para obter as informações necessárias na tomada de decisões, estão equivocadas em tentar ajustá-las a um plano de arquivamento.

Instando os arquivistas a migrarem à era pós-custodial, Gerald Ham forneceu excelentes recomendações relativas ao desenvolvimento de práticas custodiais mais eficientes, ${ }^{14}$ embora tenha passado do limite ao sugerir que os conceitos de arquivo poderiam ser dinâmicos. Ham argumentou que os arquivistas deveriam deixar de ser cataventos, "movidos pelas mudanças de humor da historiografia". Ele sugeriu que a teoria arquivística falha impedia que os arquivos urbanos fossem evidenciados, mesmo após a história urbana estar em evidência. Ham reclamou justamente da visão limitada que resultava na formação tradicional de arquivos que documentam a história dos ricos e poderosos, enquanto a história dos pobres e dos comuns é negligenciada. ${ }^{15}$ No entanto, nenhuma fórmula ou plano de ação poderia ter impedido que tais fatos ocorressem. Nenhuma teoria arquivística habilita os arquivistas a reconhecer as deficiências. Os arquivos são inevitavelmente reativos e dependentes. Os arquivistas não poderiam preencher as lacunas antes que alguém reconhecesse sua existência. Ninguém deveria criticar os arquivistas da década de 1920 por não entenderem os preconceitos de classe existentes nos arquivos, não evidenciados até a década de 1930, quando surge a escola de Annales, ou até que historiadores como Jesse Lemisch e Howard Zinn começassem a divulgar ideias semelhantes para audiências norte-americanas, na década de 1960. Se os arquivistas respondem diretamente às demandas do mercado ou tentam perceber e corrigir seus defeitos, esse mercado sempre será o ponto de referência. Nenhuma estratégia arquivística pode esperar contorná-lo. A não ser que você acredite que caso existissem teorias arquivísticas suficientemente avançadas em 1860, por exemplo, um amplo arquivo sobre o assunto

\footnotetext{
${ }^{13}$ Lytle, Richard H. Intellectual Access to Archives, American Archivist 43 (Winter 1980 and Spring 1980): p. 64-75 e p. 191-206; Berner, Archival Theory and Practice, p. 70-72.

${ }_{14} \mathrm{Ham}, \mathrm{F}$. Gerald. Archival Strategies for the Post-Custodial Era, American Archivist 44 (Summer 1981): $\mathrm{p}$. 207-16.

${ }^{15}$ Ham, F. Gerald, The Archival Edge, American Archivist 38 (January 1975): p. 5-8.
} 
"trabalho" poderia estar pronto e aguardando a chegada de John R. Commons, após ter inventado a história do trabalho em 1890.

Da mesma forma, Frank Burke propôs que os arquivistas teóricos procurem fórmulas para auxiliar os arquivistas "a superarem seu próprio ambiente social e intelectual". ${ }^{16}$ Esse é um objetivo tão inatingível e sem sentido quanto o de Ham sobre os arquivistas transcenderem o mercado. Todo arquivista, todo historiador, todo agricultor está preso em um ambiente social e intelectual. Os indivíduos devem estar cientes de seus possíveis preconceitos enquanto tentam encontrar soluções, caso a caso, para seus problemas. Arquivistas não são muito mais engenhosos que o restante da sociedade, a ponto de desenvolverem amplas teorias que os libertem de seus preconceitos.

Burke defende ainda o desenvolvimento de teorias que abarquem ideias extraídas de várias disciplinas, como Biblioteconomia, Antropologia cultural e Sociologia. Em particular, ele convida os arquivistas teóricos a incorporarem os resultados de estudos sobre gestão burocrática e tomada de decisões, a fim de produzir padrões de arquivamento com maior probabilidade de garantir a guarda dos principais documentos de uma organização. ${ }^{17}$

O trabalho inteligente dos serviços arquivísticos deve basear-se nos conhecimentos de Historiografia e Sociologia, dentre outros campos; no entanto, tal conhecimento não pode ser vertido em uma teoria arquivística coerente que seria útil. Em primeiro lugar, seria repetitivo. Caso haja teorias em organizações burocráticas que auxiliem um arquivista, seria suficiente estudar essas teorias em seu estado original. Não precisam ser lidas novamente como parte de uma teoria arquivística corta-e-cola. Os arquivistas praticantes não são tão ignorantes que necessitem ter tudo digerido pelos teóricos. Em segundo lugar, até que surja a língua Esperanto para a organização burocrática e para a criação de documentos, não pode haver um cânone do pensamento arquivístico baseado em conteúdo que seja um guia preciso para qualquer coisa. Tal constructo seria amplo ou específico demais para ser significativo. A menos que alguém se satisfaça com o mais básico dos conceitos -- uma teoria arquivística fluindo inteiramente da distinção entre díades e tríades -- seria indispensável uma mirabolante e complexa teoria de exceções. Numa agência de nível ministerial administrada com base em objetivos por um administrador, deve-se manter arquivos por tema; numa pequena corporação administrada por unidade e chefiada por um egocêntrico, deve-se manter arquivos de correspondência do chefe;

\footnotetext{
${ }^{16}$ Burke, Future Course of Archival Theory, p.43.

17 Ibid., p.42-44.
} 
numa sociedade histórica gerenciada por um conselho administrativo e chefiada por um bibliotecário, deve-se manter edições anteriores da revista Provenance. É claro que todos esses exemplos não eximem o arquivista de sua responsabilidade de aprender sobre a instituição em questão, determinando com base na realidade, e não na teoria, onde as decisões foram tomadas e como foram documentadas, e, em última análise, descartando a teoria em favor da posse dos fatos.

Burke também propõe alterar a escola teórica baseada em conteúdo para uma área na qual os próprios arquivos se tornam o assunto. Ele aconselha os arquivistas teóricos a realizarem estudos sobre as razões que levaram as sociedades a criarem documentos, sobre o lugar dos arquivos na sociedade e sobre o impulso da natureza humana de reverenciar artefatos. Parece improvável que tais questões corroborem muito para avançar o trabalho dos serviços arquivísticos. Tais indagações induziriam a respostas convencionais como "não esquecer o passado para não repeti-lo" e, provavelmente, a responsabilidade de um arquivista de salvar, manter e recuperar documentos historicamente valiosos em nada seria alterada. Ainda que valesse a pena responder a essas indagações, respondê-las está além da competência dos arquivistas. Tais questões devem ser investigadas por aqueles profissionais treinados especificamente para pesquisar fenômenos psicossociais, ou seja, sociólogos e psicólogos.

Michael Lutzker conduz esse movimento um passo adiante rumo a outras disciplinas. Ele não apenas concorda com o chamado de Burke para integrar a teoria arquivística à teoria burocrática, como também pergunta se seria "uma fantasia" sugerir que essa junção confere aos arquivistas uma compreensão exclusiva sobre as burocracias e, como resultado, um papel novo como ombudsmen burocráticos. ${ }^{18}$ Certamente, seria uma fantasia. Enquanto Gerald Ham conduziria os arquivistas à era pós-custodial, Lutzker os conduziria à era pós-arquivística. É instigante pensar que os arquivistas seriam capazes de engolir uma pílula de Schellenberg, inalar uma linha de Max Weber e observar a si mesmos tomando decisões e mediando conflitos; no entanto é cauteloso considerar que o medicamento não ajudará os arquivistas a cooperarem com pesquisadores que se recusam a retornar os documentos às suas pastas apropriadas. A fantasia de Lutzker não é sobre arquivos e sim sobre poder e status -- status esse do qual arquivistas dificilmente desfrutam e poder esse que estão desqualificados para exercer. Ainda que os conceitos arquivísticos possam esclarecer o processo das relações industriais, a utilização

\footnotetext{
${ }_{18}$ Michael A. Lutzker, Max Weber and the Analysis of Modern Bureaucratic Organization: Notes Toward a Theory of Appraisal, American Archivist 45 (Spring 1982): p. 130.
} 
de tais conceitos nesse sentido não seria uma preocupação arquivística. Uma coisa é as disciplinas tomarem emprestado conceitos entre si; outra coisa é as disciplinas se engrandecerem a partir dessa troca.

Há também aspectos sociais inquietantes além das ideias da teoria arquivística. $\mathrm{O}$ reconhecimento integral da teoria arquivística, conforme recomendado por Burke, promoveria uma estratificação doentia dentro da profissão. Burke preconiza a existência de arquivistas teóricos, os quais exerceriam carreira em tempo integral e praticariam filosofia e fariam interpretações para os arquivistas, tal como os teólogos filosofam e interpretam para os párocos. Além de contraproducente, essa divisão de trabalho é desnecessária.

A especialização funcional pode ser um imperativo no gerenciamento. Com uma miríade de demandas na agenda de um arquivista, a especialização funcional pode ser a única forma de os gestores de instituições arquivísticas, sobrecarregados e com equipe reduzida, garantirem que os funcionários concentrem a sua atenção em determinados projetos, com o prazo necessário para concluí-los. Entretanto, do ponto de vista puramente arquivístico, a especialização funcional é um erro. Nos serviços arquivísticos, as funções individuais constituem a parcela mais simples da atividade. Elas são facilmente aprendidas, facilmente executadas e não exigem atenção especializada. Mais importante, a especialização funcional diminui a importância da única coisa que torna a profissão de arquivista uma verdadeira profissão e do único recurso do qual essa profissão dispõe para contribuir com a sociedade: o conhecimento básico de cada arquivista. É a especialização no conteúdo que torna um arquivista competente, e não a sua experiência funcional. A oportunidade de executar todas as funções arquivísticas, em poucos fundos, aumenta a base de conhecimento, enquanto a especialização funcional, em diversos fundos, restringe-a.

Da mesma forma, separando cérebros arquivados dos músculos arquivados, dividindo as funções teóricas das práticas reduziria, em vez de melhorar, a compreensão dos arquivos. Como apontou o biólogo Stephen Jay Gould, "a separação entre cabeça e mão foi importante para definir e limitar o curso da ciência ao longo da história. Cirurgiões-barbeiros medievais, impelidos a lidar com baixas no campo de batalha, fizeram mais para avançar na prática da Medicina do que médicos acadêmicos, os quais raramente examinavam pacientes, baseando seu tratamento no conhecimento aprendido em. . . textos". ${ }^{19}$

\footnotetext{
${ }^{19}$ Gould, Stephen Jay. Ever Since Darwin: Reflections in Natural History (New York: W. W. Norton, 1977), p. 212-13.
} 
A melhor analogia talvez seja aquela referente aos historiadores progressistas. Tal como os arquivistas teóricos vislumbrados por Burke, os historiadores progressistas tomaram emprestado de outras disciplinas para produzirem uma concepção geral de quem eram, onde se posicionavam, porque eram historiadores, e o que o estudo acadêmico da história poderia realizar. O trabalho deles era movido por um espírito e um autoconhecimento que provavelmente se aproximava daquilo que Burke almejava para os arquivos. Mas eles não esperaram por ordens dos historiadores teóricos e nem se dedicaram à ponderação teórica. Seus avanços teóricos eram sinônimo de seu trabalho, representado, acima de qualquer outro aspecto, pelo tipo mais básico de pesquisa histórica original. Até que pessoas como Charles Beard se voltassem para a meta-história enquanto objeto de estudo, os historiadores progressistas investigavam fontes primárias ignoradas há muito tempo e produziam monografias. O seu trabalho de porcas e parafusos, suas ideias visionárias constituíam uma única e mesma atividade. As pesquisas informavam as teorias e as teorias informavam as pesquisas. Separar a função de pesquisa da função de teorização invalidaria a ambas.

Mais dois pontos sobre as implicações sociais da teoria arquivística devem ser considerados. A despeito dos contrários a Burke, ${ }^{20}$ a divisão entre "teóricos" e "práticos" criaria uma hierarquia desnecessária -- os "teóricos" dominariam os "práticos", assim como os teólogos dominam os padres das paróquias e os engenheiros dominam os mecânicos. Em campos mais exigentes, essa divisão pode ser apropriada; na área de arquivos, não. Em segundo lugar, os arquivistas teóricos, recolhidos em clausura, seguramente apresentariam novos modelos, fossem eles necessários ou não; e esses modelos seriam impostos aos arquivistas praticantes, sem dúvida, sendo viáveis ou não.

Por fim, o interesse pela teoria arquivística pode ser consequência do enorme complexo de inferioridade da profissão arquivística. Esse complexo de inferioridade permeia todas as edições da revista American Archivist, na qual os arquivistas se perguntam como podem provar a si mesmos, como podem se vender de forma mais eficaz, como podem atrair mais clientes, como podem competir por mais dólares e, geralmente, como podem ser cada vez mais parecidos com o conformista George Babbitt. ${ }^{21}$ Campanhas para certificação, conscientização

\footnotetext{
${ }^{20}$ Burke, Future Course of Archival Theory, p. 46.

${ }^{21}$ Ver, por exemplo, Dearstyne, Bruce W. What is the Use of Archives? A Challenge for the Profession, American Archivist v. 50 (Winter 1987): p. 76-87; Freeman, Elsie (Freivogel). Education Programs: Outreach as an Administrative Function, American Archivist v. 41 (April 1978): p. 147-53; Freeman, Elsie T. In the Eye of the Beholder: Archives Administration from the User's Point of View, American Archivist v. 47
} 
pública, autonomia arquivística e controle de programas de gestão de documentos parecem estimular não os desafios profissionais e sim a entediante autopromoção. A especialização funcional pode desempenhar um papel; tal divisão de trabalho teria aparência de originalidade profissional, superior àquela que imita a organização de um departamento universitário de História. A teoria arquivística está enraizada firmemente em todos esses aspectos. Como Richard Cox e outros insistiram, "o conhecimento especializado ou a teoria sistemática" é essencial para que os arquivistas usem o manto do profissionalismo. ${ }^{22} \mathrm{~A}$ teoria ter valor inerente é algo que pode ser secundário; o que conta, parece, é fazer um bom espetáculo.

Mas a teoria arquivística não é um bom espetáculo. Inúmeras de suas controvérsias são embaraçosamente insignificantes. Outras são desnecessariamente avolumadas, pois os teóricos lidam com indagações que nunca podem ser respondidas pela teoria. Grande parte da teoria consiste em abstrações exageradas sobre o óbvio. Parte da teoria é completamente estranha aos serviços arquivísticos. A teoria arquivística não desempenha o mesmo papel que a teoria em outras disciplinas. A teoria arquivística perde toda a noção do que é importante no campo, porquanto se concentra, inevitavelmente, naquilo que os arquivistas fazem e não naquilo que sabem. A teoria arquivística pode incentivar uma estrutura de classe doentia dentro da profissão. E a teoria arquivística pode emanar menos das necessidades profissionais do que dos desejos psicológicos.

Tendo asseverado todos esses aspectos, vou retroceder um pouco. Os arquivistas têm objetivos e interesses comuns, que devem ser entendidos e desenvolvidos. Quase todos as atividades, às quais me referi, oferecem sugestões de melhorias de primeira linha, e muitos dos problemas específicos que elas abordam não devem ser minimizados. Questões arquivísticas devem ser elaboradas e debatidas, deve-se buscar melhores soluções e, como profissionais, os arquivistas devem sempre avaliar seu desempenho e suas suposições.

O que questiono é a recusa deliberada de ver as árvores por causa de uma firme determinação de alucinar a existência de uma floresta. Sou cético em relação a leis universais e modelos abrangentes, e desdenhoso quanto à intelectualização sobre aspectos que não são tão difíceis. Devemos reconhecer a diferença entre investigação e investigação inteligente. Devemos ser profissionais o suficiente para analisarmos, e disciplinados o suficiente para não concordar

(Spring 1984): p. 111-23; e Cox, Richard J. Professionalism and Archivists in the United States, American Archivist v. 49 (Summer 1986): p. 229-47.

${ }^{22}$ Cox. Professionalism, p. 232. 
com arquivos temáticos, aplicando técnicas desconstrucionistas a informações nas etiquetas das caixas ou perseguindo outras investigações estúpidas, mas aparentemente pomposas. Os arquivistas ganham notoriedade quando conversam com a sociedade sobre os documentos sob seus cuidados. Nesse sentido, às vezes, os arquivistas precisam conversar entre si sobre as suas atividades. Mas é fácil afastar-se muito do ponto final de utilidade. Cada vez mais, estamos conversando sobre nós mesmos, e isso não é teoria. É narcisismo.

Apaixonada por quimeras como teoria arquivística, relações públicas, certificação e especialização funcional, a nossa profissão está se movendo na direção errada. Está se movendo em direção ao artificial, ao autocentrado e ao trivial, e está se afastando do substancial, do socialmente útil e do envolvente. Se continuarmos assim, nos transformaremos em uma multidão de colegas de escola, hipnotizados com o equivalente arquivístico de quantos anjos podem dançar na cabeça de um alfinete. 